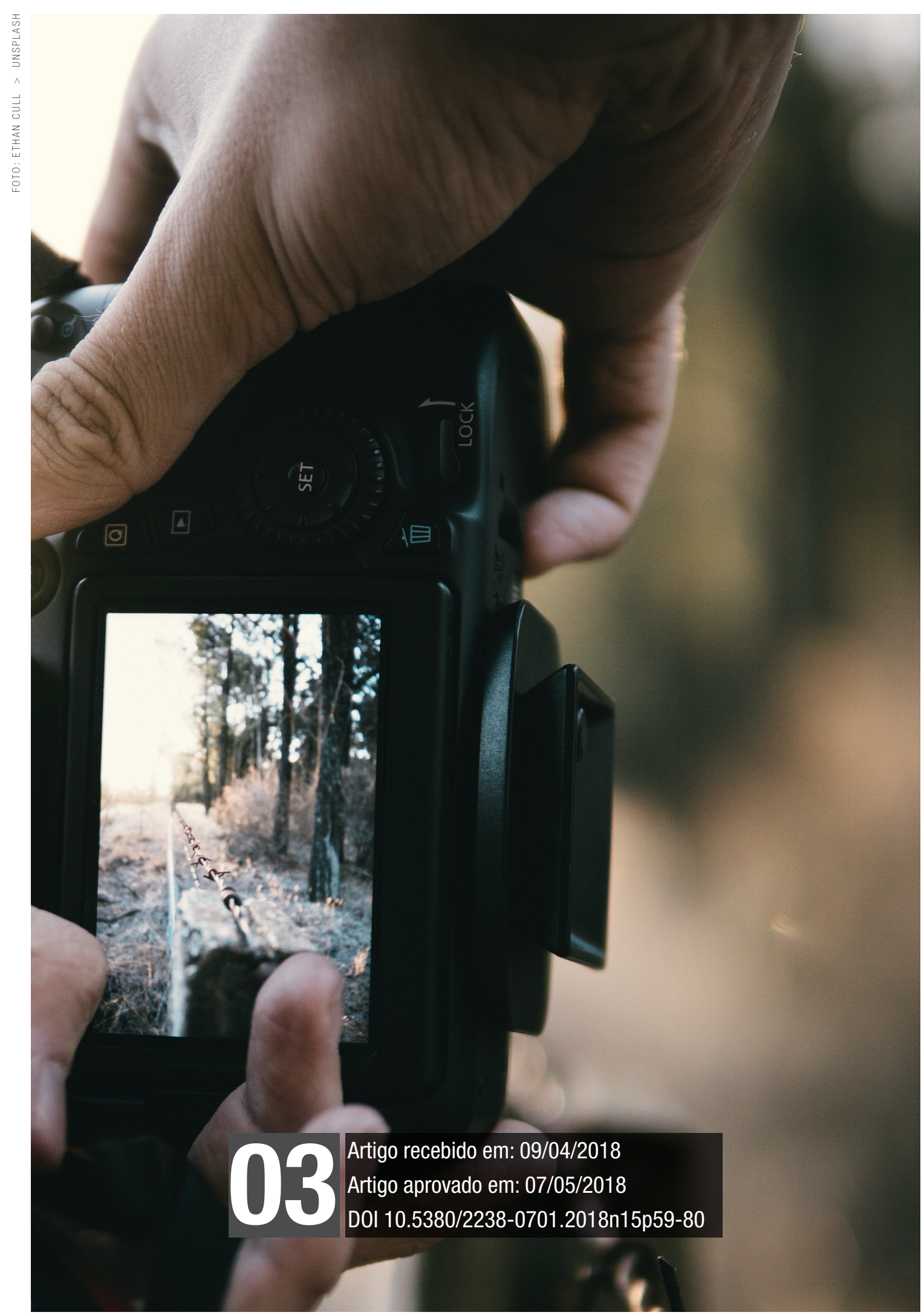


Teoria do agendamento; Definidores da notícia; Amazônia; Reserva ambiental; Sindromes do jornalismo ambiental. 


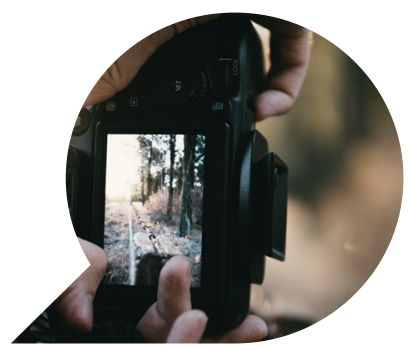

\section{As vozes da agenda-setting no jornalismo ambiental: a identificação dos definidores das notícias e das síndromes da cobertura da extinção da Renca na Amazônia em sites do Amapá}

Las voces de la agenda-setting en el periodismo ambiental: la identificación de los definidores de las noticias y de los síndromes de la cobertura de la extinción de Renca en la Amazonia en sitios de Amapá

The voices of the agenda-setting in environmental journalism:

the identification of the definers of the news and the syndromes of the coverage of the extinction of the Renca in Amazonia in sites of Amapá

PAULA MELANI ROCHA ${ }^{1}$

ABINOAN SANTIAGO DOS SANTOS ${ }^{2}$

Resumo: A proposta do artigo é analisar a imprensa periférica, sobretudo as características do agendamento da mídia da Amazônia quanto

1 Pós-doutora em Jornalismo pela Universidade Fernando Pessoa, professora do Programa de Pós-Graduação Mestrado em Jornalismo e do Departamento de Jornalismo da Universidade Estadual de Ponta Grossa (UEPG).

2 Mestrando em Jornalismo pela Universidade Estadual de Ponta Grossa (UEPG). 
a temas da própria região. O objetivo é identificar quais as vozes definidoras das notícias de três sites jornalísticos do Amapá na cobertura da extinção da Reserva Nacional de Cobres e Associados (Renca), área de proteção mineral entre os territórios amapaense e paraense. Além da teoria do agendamento, este trabalho se baseia na identificação dos definidores da notícia em consonância com o papel jornalístico em questões ambientais, a partir de suas síndromes e análise de reportagem como caminho metodológico. Como corpus analisou-se a semana de 23 a 30 de agosto de 2017, a primeira após o anúncio de extinção da Renca. Nesse período, houve a predominância de definidores de caráter político em detrimento das comunidades afetadas pela decisão.

Palavras-chave: Teoria do agendamento; Definidores da notícia; Amazônia; Reserva ambiental; Síndromes do jornalismo ambiental.

Resumen: La propuesta del artículo es analizar la prensa periférica, sobre todo las características de la programación de los medios de la Amazonía en temas de la propia región. El objetivo es identificar cuáles son las voces definitorias de las noticias de tres sitios periodísticos de Amapá en la cobertura de la extinción de la Reserva Nacional de Cobres y Asociados (Renca), área de protección mineral entre los territorios amapaense y paraense. Además de la teoría de la programación, este trabajo se basa en la identificación de los definidores de la noticia en consonancia con el papel periodístico en cuestiones ambientales, a partir de sus síndromes y análisis de reportaje como camino metodológico. Como corpus se analizó la semana del 23 al 30 de agosto de 2017, la primera después del anuncio de extinción de Renca. En ese período, hubo la predominancia de definidores de carácter político en detrimento de las comunidades afectadas por la decisión.

Palabras-llave: Teoría de la programación; Definidores de las noticias; Amazonas, Reserva ambiental; Síndromes del periodismo ambiental.

Abstract: The purpose of this article is to analyze the peripheral press, especially the characteristics of the media agenda of the Amazon region. The aim is to identify the defining voices of the news from three journalistic sites of Amapa in the coverage of the extinction of the National Reserve of Cobres and Associates (Renca), an area of mineral protection between the Amapaense and Paraense 
territories. In addition to the scheduling theory, this work is based on the identification of the definers of the news in consonance with the journalistic paper on environmental issues, from their syndromes and analysis of reporting as a methodological path. The corpus was analyzed the week of August 23rd to 30th, 2017, the first after the announcement of the extinction of Renca. In this period, there was the predominance of political definers to the detriment of the communities affected by the decision.

Keywords: Agenda-setting theory; News definers; Amazon; Environmental reserve; Syndromes of environmental journalism. 


\section{Introdução}

Criada em 1984, a Reserva Nacional de Cobres e Associados (Renca) chamou atenção da mídia brasileira no segundo semestre de 2017. $\mathrm{O}$ foco se deu por um decreto do presidente Michel Temer (MDB) que a extinguiu em 23 de agosto, abrindo possibilidade para investimentos estrangeiros naquelas terras, às proximidades da fronteira brasileira com o Platô das Guianas ${ }^{3}$. A medida se colocou na contramão do motivo nacionalista da existência da Renca: a proteção contra o capital de outros países na Amazônia.

A área tem características de interesses empresariais. Praticamente ainda intocada - sendo explorada apenas para subsistência de ribeirinhos e indígenas -, o território tem quatro milhões de hectares, maior que estado do Espírito Santo. Desde a sua criação, as pesquisas minerais são da tutela do Governo Federal. Mas não houve avanço, mesmo com mais de 700 pedidos de mineradoras para explorar a Renca, farta em ouro, manganês e ferro.

A questão mineral se colocou como o mote para a formação da Renca, mas sua inatividade contribuiu para proteger a floresta da região. Desde a sua criação, se estabeleceram na área sete reservas de preservação ambiental e duas terras indígenas, restando $20 \%$ de seu território total para o minério. Esse risco iminente a essas regiões protegidas por lei gerou críticas ao decreto de extinção da Renca.

Além disso, a extinção ocorreu sem diálogo com a população local, deixando o governo mais pressionado por parte da mídia, aliados políticos, Organizações Não Governamentais (ONGs) e classe artística, que se posicionaram contra a medida. Em meio a defesa da sua segunda denúncia criminal ofertada pela Procuradoria Geral da República, o presidente Temer voltou atrás e revogou o decreto em 26 de setembro para evitar mais desgastes.

Após esse breve contexto, este artigo aborda como ocorreu o agendamento do tema por sites jornalísticos próximos à realidade geográfica da Renca, distante dos grandes centros. Além da agenda-setting (MCCOMBS, 2009), o trabalho tem como norte teórico a identificação das fontes definidoras das notícias (HALL ET AL, 2016) sobre o tema a fim de saber

3 O Platô das Guianas fica no extremo Norte da América do Sul. É formado por Suriname (emancipado da Holanda em 1975) e Guiana (independente da Inglaterra em 1966) e pelo território francês Guiana Francesa. Devido a relações econômicas, políticas e culturais, o Amapá é considerado como a "Guiana Portuguesa” (CAVLAK, 2015). 
quais as vozes (SCHMITZ, 2011) presentes no debate na mídia amazônica. Além disso, partimos do pressuposto de que, mesmo próximos à Renca, os conteúdos jornalísticos tiveram como principais atores a classe política em detrimento aos índios e ribeirinhos, povos diretamente afetados. Ao fim, espera-se relacionar essas fontes em consonância com as síndromes do jornalismo ambiental definidas por Bueno (2007).

Metodologicamente, a apreensão do objetivo deste trabalho é por análise dos conteúdos jornalísticos (HERCOVITZ, 2007) produzidos sobre a Renca pelos sites Diário do Amapá, G1 Amapá e SelesNafes. Com. Todos sediados em Macapá e foram escolhidos por serem os mais tradicionais em atividade no mercado local. No Pará, houve um silenciamento do tema por dois veículos tradicionais: O Liberal e Diário do Pará. No primeiro, apenas cinco notícias de agências foram publicadas, a partir da terceira semana após o decreto presidencial. No segundo, não existiu nenhuma reportagem sobre o caso. Frisa-se que O Liberal é do Grupo RM de Comunicação, com ligação ao PSDB local; e o Diário do Pará é do RBA Comunicação, da família do senador Jader Barbalho (MDB), que tem como filho Helder Barbalho, ex-ministro da Integração Nacional no governo Temer.

O período do recorte é de 23 a 30 de agosto de 2017, intervalo referente à primeira semana de cobertura do caso. A coleta chegou a 20 notícias e teve como unidade de registro o corpo do texto. Para Herscovitz (2007), esse método é empregado pelo jornalismo para detectar três aspectos: enquadramentos, agendamentos e tendências. A segunda perspectiva é a que interessa para este artigo.

Os três sites são considerados regionais com base nas áreas de cobertura e de circulação. O G1 faz parte do Grupo Globo e chegou ao Amapá em 07 de junho de 2013, sendo Macapá a penúltima capital do país a ser contemplada pelo projeto de extensão nacional do G1. O site local tem 16 páginas e, atualmente, emprega oito jornalistas. O Diário do Amapá (DA), criado em 1993, aparece na vanguarda como o primeiro jornal impresso do estado a migrar para a plataforma online, em 2000, transpondo o mesmo conteúdo do impresso para o digital. Contudo, somente em 2014 o DA assumiu a configuração de um jornal online, com produção de conteúdo voltado para a internet. A mesma empresa que administra o Diário do Amapá também detém uma rádio, uma revista e uma TV na WEB. Ao todo, são dez profissionais que trabalham no conteúdo do site. Lançado em dezembro de 2013, O SelesNafes.Com 
foi o segundo veículo amapaense a se caracterizar como um site jornalístico. O nome se deve ao seu idealizador, o jornalista Seles Nafes, ex-apresentador de um telejornal na cidade. $\mathrm{O}$ site conta com oito editorias e seis profissionais.

Como caminho didático para compreensão contextual do artigo, é necessário abordar conceitualmente a teoria do agendamento, as síndromes do jornalismo ambiental, detalhar como se deu a cobertura do tema nos sites pesquisados e, por fim, apresentar a análise dos dados.

\section{Agenda-Setting}

Influenciada por Walter Lippman, a hipótese da agenda-setting (agendamento, em português) teve o seu primeiro estudo desenvolvido em 1972 por Maxwell McCombs e Donald Shaw. Desde o início dos estudos, a essência da agenda se ancora na obra Opinião Pública, de Lippman (2010), em especial no primeiro capítulo, que trata da apreensão da complexidade do mundo pelas pessoas, o que se dá a partir das “imagens pintadas” pelos meios de comunicação. Ou seja, por não termos contato com a realidade de forma ampla, a mídia é o elo entre a nossa mente a o mundo distante e/ou diferente do nosso cotidiano e com isso causa efeitos sobre o que pensarmos.

Foi de acordo com esse espectro conceitual que McCombs e Shaw aplicaram o primeiro estudo tendo como objeto as eleições presidenciais norte-americana de 1968, em Chapell Hill, na Carolina do Norte, para verificar a influência da mídia na agenda dos eleitores em relação a temas importantes para o país (MCCOMBS, 2009). "Enquanto muitos temas competem pela atenção do público, somente alguns são bem-sucedidos em conquistá-los, e os veículos noticiosos exercem influência significativa sobre nossas percepções sobre quais são os assuntos mais importantes do dia" (MCCOMBS, 2009, p.19).

Cabe ressaltar que, para a hipótese da agenda-setting, os meios de comunicação influenciam a agenda dos assuntos abordados pelas pessoas no cotidiano, e não a maneira como eles devem ser abordados. No caso específico de Chapell Hill, a hipótese teve como teste a comparação de duas evidências: a descrição da agenda pública, o conjunto de temas que era grande preocupação dos eleitores; e a descrição dos temas das agendas dos veículos noticiosos utilizados como corpus e por aqueles eleitores.

De acordo com McCombs (2009), a pesquisa - que utilizou questionários e elaborou um ranking com os temas do dia mais citados pelos 
entrevistados indecisos, independentemente se estava ou não na agenda dos candidatos à presidência dos Estados Unidos - mostrou que cinco temas dominaram tanto a agenda pública quanto a midiática na campanha de 1968. "Havia quase uma correspondência perfeita entre os rankings destes temas entre os eleitores de Chapell Hill e seus rankings baseados na apresentação destes temas pelos veículos de comunicação" (MCCOMBS, 2009, p.25).

Apesar disso, é rechaçada a percepção de que a hipótese da agenda-setting representa o retorno ao conceito da teoria hipodérmica. Os receptores da audiência não são considerados autômatos pela programação noticiosa. Em outras palavras, a mídia não exerce um poder ilimitado sobre as pessoas. A necessidade de orientação social é a questão-chave para o seu funcionamento. Quanto maior o nível de conhecimento do público sobre determinada temática, menor é o efeito de agenda pela mídia e vice-versa.

Outro ponto da teoria é o de que existe uma instância de mediação entre o público e o sistema político. Esse elo entre ambos seria desempenhado pelo jornalismo, determinando assim como um elemento da agenda pública, conforme citado anteriormente. Tal agenda está enraizada pela complexidade do mundo social, ou seja, ela não seria apenas o agrupamento de fatos do cotidiano, mas a reunião daqueles temas considerados problemas da ordem social.

Além disso, os fatores tempo e espaço podem ser levados em consideração para explicar a percepção de uma maior presença de temas de caráter social. Em todos os tipos de veículos de mídia há uma limitação no tratamento dos assuntos. Isso ocorre até em sites. Mesmo com possibilidade de criação de dezenas de conteúdo em um único canal na web, as páginas têm seus limites.

Mesmo tendo se consolidado no contexto político, em especial no aspecto eleitoral, a agenda-setting não se limita a esse tipo de pesquisa, podendo ser usada também em demais áreas de conhecimento, como a do meio ambiente. Este trabalho não pretende analisar os efeitos da cobertura da extinção da Renca sobre a audiência. Mas diante do escopo conceitual de McCombs (2009), partimos do pressuposto de que o evento atravessou tanto a agenda da mídia quanto a do público. Nesse sentido, reitera-se que o foco é analisar como os conteúdos que formaram essas agendas foram apresentados pelo Diário do Amapá, G1 Amapá e SelesNafes.Com. 
A afirmação de que a extinção da Renca permeou a agenda do público se dá, principalmente, pelo volume de reportagens produzidas pelos três sites estudados na primeira semana após o fim da reserva. Isso indica que houve a necessidade de orientação sobre o tema em razão do desconhecimento sobre a própria área. Ao investigar como a agenda da mídia se apresentou, cabe verificar eventuais falhas praticadas pelo jornalismo ambiental, consideradas como síndromes por Bueno (2007).

\section{Os definidores das notícias}

Se, conforme verificado, a mídia agenda e, assim, se torna um elemento para formação da opinião pública, como os veículos de comunicação são agendados? Para McCombs (2009), as fontes das notícias são as responsáveis por esse movimento inverso. Isso propicia assim um jogo de poder entre os definidores e a imprensa, impulsionado pela busca de visibilidade dessas fontes na esfera pública através da mídia.

As fontes como elementos principais para o agendamento dos veículos de comunicação são classificadas como "definidores primários". Segundo Hall et al (2016, p.228), "os media não criam notícias; melhor, estão dependentes de assuntos noticiosos específicos fornecidos por fontes institucionais regulares e credíveis". Duas razões explicam isso: o fator tempo de pressão interna nas redações e a busca pela imparcialidade, objetividade e equilíbrio. Já a mídia é colocada como definidora secundária por reproduzir discursos dos "poderosos" que habitualmente possuem um acesso mais fácil aos jornalistas.

Como saber quais foram os definidores primários no evento da extinção da Renca? Optou-se fazer a referida identificação com base na sistematização das fontes de notícias classificadas por Schmitz (2011): especialistas, referência, testemunhal, institucional, notável, empresarial, oficial e popular. Pelo conceito de cada uma, conforme exposto no quadro a seguir, é possível verificar se existiu alguma das síndromes do jornalismo ambiental no tratamento do assunto. 
Quadro 1: Classificação das fontes

\begin{tabular}{|c|l|}
\hline Oficial & $\begin{array}{l}\text { Alguém que se pronuncia em função do cargo público que } \\
\text { exerce por órgãos mantidos pelo Estado, sejam eles do } \\
\text { executivo, legislativo ou judiciário. }\end{array}$ \\
\hline Empresarial & $\begin{array}{l}\text { Representa uma corporação empresarial da indústria, } \\
\text { comércio, serviços ou do agronegócio. }\end{array}$ \\
\hline Institucional & $\begin{array}{l}\text { É quem representa um organização sem fins lucrativos ou } \\
\text { grupo social. }\end{array}$ \\
\hline Popular & $\begin{array}{l}\text { Manifesta-se por si mesmo, geralmente uma pessoa co- } \\
\text { mum, que não fala por uma organização ou grupo social. }\end{array}$ \\
\hline Notável & $\begin{array}{l}\text { São pessoas notáveis pelo seu talento ou fama, geralmente } \\
\text { artistas, escritores, esportistas, profissionais liberais, per- } \\
\text { sonalidades políticas, que falam de si e de seu ofício. }\end{array}$ \\
\hline Testemunhal & $\begin{array}{l}\text { Funciona como álibi para a imprensa, pois representa aqui- } \\
\text { lo que viu ou ouviu, como partícipe ou observadora. }\end{array}$ \\
\hline Especialista & $\begin{array}{l}\text { Trata-se de pessoa de notório saber específico (especialista, } \\
\text { perito, intelectual) ou organização detentora de um conhe- } \\
\text { cimento reconhecido. }\end{array}$ \\
\hline Aplica-se à bibliografia, documento ou mídia que o jorna- \\
lista consulta.
\end{tabular}

Fonte: Schmitz (2011).

\section{As síndromes do jornalismo ambiental}

Uma característica do jornalismo ambiental é sua complexidade. Por ser interdisciplinar, ele também aborda os campos econômicos, políticos, biológicos, sociológicos e culturais. Dornelles e Grimberg (2012, p.69) consideram que a notícia do jornalismo ambiental em termos técnicos não difere de outras especialidades, "tampouco possui fontes fixas e exclusivas, ou mesmo um tema específico. Na verdade, é nesse último aspecto que reside à complexidade da temática ambiental".

Para Bueno (2007, p.35), em sua essência, o jornalismo ambiental tem funções informativa, política e didática, além de poder ser defini- 
do como o processo de produção e circulação de informações (conhecimentos, saberes, resultados de pesquisas etc.) comprometidas com a temática de meio ambiente para qualquer tipo de público, desde o leigo até o especializado. Ressalta-se que interesses econômicos e empresariais podem afetar a abordagem de questões ambientais, relativizando o comprometimento do jornalismo ambiental com o cuidado da natureza e difusão de conhecimento sobre o tema.

Mesmo com sua consolidação, pragmaticamente, o espaço destinado ao jornalismo ambiental ainda está aquém em relação às demais áreas de cobertura jornalística, em especial ao político e ao policial, nas páginas dos jornais impressos, sites, TVs e rádios (MOTA, 2010; DORNELLES; GRINBERG, 2012; TEIXEIRA, 2014). Sobre esse aspecto, Bueno (2007, p.37) considera que "o jornalismo ambiental brasileiro tem se caracterizado, sobretudo, por algumas síndromes, equívocos formidáveis que têm impedido o cumprimento das funções anteriormente apontadas" (política, informativa e didática). Pelo menos cinco síndromes são apontadas pelo autor.

Quadro 2: Síndromes do jornalismo ambiental

\begin{tabular}{|l|l|}
\hline $\begin{array}{l}\text { Síndrome do } \\
\text { zoom ou do } \\
\text { olhar vesgo }\end{array}$ & $\begin{array}{l}\text { Tem relação com a redução da interdisciplinaridade do jornalis- } \\
\text { mo ambiental a um aspecto, seja ele político, econômico, factual, } \\
\text { científico etc. sendo uma cobertura segmentada. }\end{array}$ \\
\hline $\begin{array}{l}\text { Síndrome do } \\
\text { muro alto }\end{array}$ & $\begin{array}{l}\text { Nessa síndrome, há a tentativa de despolitização do debate am- } \\
\text { biental e uma vinculação à perspectiva empresarial em detrimento } \\
\text { ao político, econômico ou sociocultural. Também é caracterizado } \\
\text { por elites e exclusão dos cidadãos ou representantes de segmentos } \\
\text { sociais. }\end{array}$ \\
\hline $\begin{array}{l}\text { Síndrome da } \\
\text { lattelização das } \\
\text { fontes }\end{array}$ & $\begin{array}{l}\text { É o desdobramento da segunda síndrome. Nela, a cobertura é } \\
\text { baseada em fontes de especialistas, pesquisadores e professores de } \\
\text { instituições de ensino. }\end{array}$ \\
\hline $\begin{array}{l}\text { Síndrome das } \\
\text { indulgências } \\
\text { verdes }\end{array}$ & $\begin{array}{l}\text { Para Bueno (2007), sua caracterização está no cinismo em prol } \\
\text { do "marketing verde" a favor da depredação e promoção de dois } \\
\text { objetivos: alcançar a aceitação de empresas e a de soluções am- } \\
\text { bientais como forma de neutralizar ações predatórias, a exemplo } \\
\text { de reflorestamento para absorver carbono. }\end{array}$ \\
\hline
\end{tabular}




\begin{tabular}{|l|l|}
$\begin{array}{l}\text { Síndrome da } \\
\text { baleia enca- } \\
\text { lhada }\end{array}$ & $\begin{array}{l}\text { Nessa síndrome, a cobertura tem como base o sensacionalismo } \\
\text { da temática, algo bastante presente principalmente em notícias } \\
\text { de desastres ambientais pautadas sob a ótica do factual ou pelo } \\
\text { esotérico, sem qualquer investigação do problema. }\end{array}$ \\
\hline
\end{tabular}

Fonte: Bueno (2007)

\section{O agendamento na extinção da Renca}

Inicialmente, o levantamento contemplou de 23 de agosto a 27 de setembro - respectivas datas da extinção da Renca e o dia seguinte à revogação do decreto. Nesse período, o Diário do Amapá, G1 Amapá e SelesNafes.Com publicaram 48 textos. Optou-se, porém, por analisar a primeira semana porque foi o intervalo com mais publicações, com 20 notícias. O restante apareceu diluído nas semanas seguintes. As distribuições estão na tabela abaixo:

Tabela 1: Distribuição das notícias sobre a Renca de acordo com o período de publicação e site responsável

\begin{tabular}{|c|c|c|}
\hline Site & $\begin{array}{c}\text { 23 de agosto a } \\
27 \text { de setembro }\end{array}$ & 23 a 30 de agosto \\
\hline Diário do Amapá & 21 & 8 \\
\hline G1 Amapá & 12 & 6 \\
\hline SelesNafes.com & 15 & 6 \\
\hline Total & 48 & 20 \\
\hline
\end{tabular}

Fonte: do autor (2018)

De acordo com as oito tipologias de Schmitz (2011), constatou-se que os 20 textos sobre a extinção da Renca tiveram 24 definidores como fontes, divididas em cinco categorias. Chama atenção a ausência, nos sites do Amapá, de fontes "notáveis" e "empresariais" (SCHMITZ, 2011), uma vez que artistas e celebridades fizeram protestos contra a medida presidencial e que empresas já haviam solicitado permissão para explo- 
rar a área. Outra classificação que não apareceu foi a "testemunhal”, habitualmente utilizada em eventos de caráter factual (SCHMITZ, 2011), o que não é o caso. Do total, a maioria usada na cobertura era "oficial". As de "referência" apareceram em menor frequência entre os conteúdos, conforme mostra a Tabela 2.

Tabela 2: Classificação dos definidores na cobertura da extinção da Renca de acordo com os sites analisados

\begin{tabular}{|c|c|c|c|c|}
\hline Tipos & $\begin{array}{c}\text { Diário do } \\
\text { Amapá }\end{array}$ & G1 Amapá & SelesNafes & Total \\
\hline Especialista & - & 2 & - & 2 \\
\hline Referência & - & - & 1 & 1 \\
\hline Institucional & 4 & 2 & - & 6 \\
\hline Oficial & 4 & 4 & 5 & 13 \\
\hline Popular & - & 1 & 1 & 2 \\
\hline Total & $\mathbf{8}$ & $\mathbf{9}$ & $\mathbf{7}$ & $\mathbf{2 4}$ \\
\hline
\end{tabular}

Fonte: do autor (2018)

Algumas constatações são pertinentes do ponto de vista de como se deu a cobertura da extinção da Renca a partir das fontes. No Diário do Amapá, por exemplo, o número de definidores é igual ao número de publicações. Isso significa que apenas um tipo de fonte apareceu em cada publicação, demonstrando o alto poder desses definidores na cobertura jornalística (HALL ET AL, 2016). Essa constatação indica a falta de contraposição, pluralidade e interdisciplinaridade que o jornalismo ambiental requer (BUENO, 2007). Além disso, todas as fontes oficiais se limitaram à mesma pessoa no Diário do Amapá: o senador Randolfe Rodrigues (Rede-AP), oposição ao governo Temer. Das fontes institucionais, duas eram diretórios regionais de partidos oposicionistas ao presidente: PSB e PSOL. Esse aspecto evidencia o teor político dado pelo Diário. Segundo Schmitz (2011), o uso das fontes oficiais, de fato, é a preferida da mídia, embora possa falsear a realidade, para preservar 
seus interesses ou do grupo político ao qual pertence. Quando se trata de questões ambientais, o discurso oficial reproduzido por jornalistas dificulta a existência de uma informação interdisciplinar ao cidadão, conforme evidencia Bueno (2007).

As outras duas fontes do Diário do Amapá são o Ministério Público Federal (MPF) e a Diocese de Macapá, que também se mostraram contra a extinção. Como ilustração, os títulos das reportagens com esses definidores já indicam influência exercida por elas, devido ao uso dos termos "luta", "atacar" e "defesa". Elas podem ser identificadas nos títulos "Congresso Estadual do PSB tem como foco a defesa da Renca, desenvolvimento sustentável e o futuro do Amapá", "Randolfe pede apoio do Papa na lutacontra extinção da Renca" e "MPF/AP complementa ação para atacar novo decreto de extinção da Renca”.

É importante destacar, aliás, que Randolfe Rodrigues aparece como definidor em outras três oportunidades na semana pesquisada, sendo duas no SelesNafes.Com e uma no G1 Amapá. Esses referidos sites foram, ainda, os únicos a utilizarem fontes populares em duas ocasiões, o que, para Bueno (2007), é imprescindível em coberturas ambientais sobre medidas que atingem diretamente a vida das pessoas. A definição primária das referidas notícias se deu por um índio da aldeia Waiãpi e um ribeirinho extrativista, no SelesNafes.Com e G1 Amapá, respectivamente. No caso do uso do discurso do indígena, a notícia utilizou apenas o dele como definidor primário, indicando influência no posicionamento da reportagem, conforme demonstra o título: "Absurdo", diz chefe Waiãpi sobre fim de reserva mineral na Amazônia. Por outro lado, apesar de o extrativista ser fonte do G1 Amapá, ele não foi o único definidor da notícia. O conteúdo também teve uma especialista (ecologista) como fonte na reportagem "No AP, 'aula aberta' discute consequências da extinção da Renca para a população". O título pode indicar o que Hall et al (2016) classificaram como a busca pelo "equilíbrio", "imparcialidade" e "objetividade", afinal, o enunciado demonstra generalidade em detrimento dos discursos contrários e a favor da Renca contidos no texto.

Mesmo que de forma sintética, a identificação desses definidores primários e a forma como foram utilizados são fundamentais para alcançar outro objetivo deste artigo: identificar as síndromes do jornalismo ambiental na cobertura da Renca. As cinco síndromes definidas por Bueno (2007) foram encontradas no tratamento do assunto pelos sites pesquisados. A predominante foi a do "zoom ou olhar vesgo", presente 
em 13 dos 20 conteúdos, sobretudo no Diário do Amapá. Todas as oito reportagens do veículo se encontravam nessa condição, sendo que duas ainda se somavam a uma segunda síndrome, a da "baleia encalhada". Essa, aliás, aparece logo em seguida, em três reportagens do total. Ambas as síndromes abrangerem 16 conteúdos. A tabela a seguir expõe as síndromes identificadas em cada site pesquisado.

Tabela 3: As síndromes do jornalismo ambiental na cobertura da extinção da Renca

\begin{tabular}{|c|c|c|c|c|}
\hline Tipos & $\begin{array}{c}\text { Diário do } \\
\text { Amapá }\end{array}$ & G1 Amapá & SelesNafes & Total \\
\hline Zoom & 8 & 1 & 4 & 13 \\
\hline $\begin{array}{c}\text { Indulgências } \\
\text { verdes }\end{array}$ & - & 1 & 1 & 2 \\
\hline $\begin{array}{c}\text { Baleia encal- } \\
\text { hada }\end{array}$ & 2 & - & - & 3 \\
\hline Muro alto & - & 2 & - & 2 \\
\hline Lattelização & - & $\mathbf{5}$ & $\mathbf{6}$ & $\mathbf{2 1}$ \\
\hline Total & $\mathbf{1 0}$ & & & 1 \\
\hline
\end{tabular}

Fonte: do autor (2018)

Um caso de texto com as síndromes do "zoom ou olhar vesgo" e da "baleia encalhada" é o já citado "Randolfe pede apoio do Papa na luta contra extinção da Renca”, publicado em 30 de agosto, no Diário do Amapá. Para Bueno (2007), “o zoom ou olhar vesgo” é caracterizado pela diminuição do olhar a uma perspectiva, seja ela econômica, política, científica etc. Com apenas uma fonte de notícia, o processo de segmentação da Renca a uma única visão acaba sendo consequência, como aconteceu em 13 reportagens que se valeram de apenas um definidor primário. No caso da "síndrome da baleia", o sensacionalismo se torna a marca da cobertura: "é certamente um flagrante trágico da degradação ambiental, mas os veículos veem nela apenas uma forma plástica de 
ilustrar as suas páginas e telas, sem investigar o fenômeno" (BUENO, 2007, p. 38). Para Scharf (2004), a cobertura jornalística levada a essa dinâmica propicia um olhar segmentado, sem a devida preocupação com o que permeia os eventos, deixando as pessoas sem saber das eventuais motivações que atravessam as questões ambientais.

O trecho a seguir, extraído da reportagem "Randolfe pede apoio do Papa na luta contra extinção da Renca”, é exemplar para ilustrar as duas síndromes, principalmente a apropriação da tragédia ambiental materializada apenas no discurso político, sem investigação ou informação complementar contextualizada para confrontar a declaração da fonte.

O senador Randolfe Rodrigues (REDE - AP) recorreu à Conferência Nacional dos Bispos do Brasil (CNBB) contra o decreto presidencial que extingue a Reserva Nacional de Cobre e Associados (Renca) e libera a área para exploração mineral. Randolfe pede apoio da conferência para conseguir uma declaração do Papa Francisco em nome da luta pela Amazônia. (...) O senador lembrou ainda que o impacto da mineração na Amazônia sempre resultou em tragédia e morte, além da péssima experiência que o estado teve, por exemplo, com a mineradora inglesa Zamim. "Por onde a mineração passou no Amapá deixou amplíssima devastação ambiental” (DIÁRIO DO AMAPÁ, 2017)

Uma síndrome identificada que chama atenção é a da "indulgências verdes”. Nela, segundo Bueno (2007), a principal característica é a postura hipócrita e cínica de empresas e jornalistas que praticam o chamado "marketing verde" com propósito de convencer que haverá desenvolvimento através de medidas que degradem o meio ambiente. Habitualmente, esse tipo de conteúdo está em editoriais ou em colunas. Essa síndrome é ilustrada no texto "Exploração mineral na Amazônia: histeria no paraíso", publicada em 28 de agosto no SelesNafes.Com. Assinado pelo próprio dono do site, o jornalista Seles Nafes, o tom editorial mostra a posição do veículo sobre o caso. A proposta defendida nos parágrafos é a de que a exploração da Renca pode gerar empregos aos amapaenses, além de, em tom irônico, classificar a região como um paraíso. Apesar de não parecer ter uma relação direta de forma explícita, cabe destacar a ligação entre Seles Nafes e o empresário e senador Davi Alcolumbre (DEM-AP), vice-líder do governo Temer. O jornalista chegou a trabalhar na comunicação da campanha do político para o Senado, em 2014. 
Ao mesmo tempo em que é preciso estabelecer medidas fortes de controle e fiscalização sobre os projetos que serão habilitados para explorar o nosso subsolo, também é preciso entender que essas riquezas necessitam ser monetizadas. Afinal, realmente não estamos num museu ou num Paraíso [grifo nosso]. Pode até parecer lugar comum, mas a exploração de minério, mesmo que dentro da floresta amazônica, vai sim gerar desenvolvimento, renda e empregos. Isso mesmo, empregos. É o que a gente precisa por aqui, depois de quase 4 anos de recessão brasileira. (...) É óbvio que existe um grande interesse político e econômico por trás do decreto. Sempre há. O que não está certo é abrirmos mão de gerar os empregos que a nossa gente precisa quando é perfeitamente possível liberar áreas de extração exigindo medidas que compensem os danos. Existe legislação suficiente para isso. E vamos ser realistas: com o apoio político que Temer tem no Congresso, dificilmente o decreto será anulado. (SELESNAFES.COM, 2017)

De acordo com Bueno (2011, p.3), é considerado um constrangimento para jornalistas a reprodução de posicionamentos de fontes na tentativa do uso do discurso de desenvolvimento sustentável como forma de camuflar interesses que podem estar por trás de temas ambientais.

O desenvolvimento não se resume a esta perspectiva meramente econômico-financeira, que não apenas empobrece o conceito, mas o desvirtua brutalmente. Desenvolvimento tem a ver com a superação da pobreza e da desigualdade, com a defesa intransigente da pluralidade e da diversidade, com o compromisso com os direitos humanos, com o acesso à educação, à moradia e assim por diante. Crescimento econômico é outra coisa e, em muitos casos, representa um olhar antagônico que, no capitalismo selvagem ou predador, se antepõe à implementação de um efetivo desenvolvimento (o social, o cultural, o das liberdades de pensamento e expressão) (BUENO, 2011, p.5)

Outro destaque é para o registro da síndrome do "lattes", pautada exclusivamente pelas declarações racionais de pesquisadores ou especialistas das academias. Bueno (2007) não demonstra ser contra o uso de fontes desse tipo, mas pondera que a sua utilização deve ser equilibrada com a de cidadãos comuns. Essa síndrome foi verificada no G1 Amapá, no texto "Quatro rios do AP têm peixes com nível elevado de mercúrio, aponta estudo", publicado em 29 de agosto de 2017. 
Para os ribeirinhos que comem peixe praticamente todo dia e que têm uma dieta basicamente representada por proteína de peixe, esse dado é preocupante. Talvez esse valor seja alto demais para o consumo humano no nosso estado, comentou a doutora em zoologia do Iepa, Cecile Gama. (G1 AMAPÁ, 2017)

O referido trecho representa a preocupação com os possíveis danos da mineração, em especial a contaminação de rios, principal fonte de subsistência dos ribeirinhos. Porém, não há declaração dos afetados, o que, para Bueno (2007), se torna uma falha por não contextualizar as declarações de especialistas e por tratar do assunto de modo estritamente tecnicista.

\section{Considerações finais}

Com base na análise da primeira semana da cobertura de sites amapaenses sobre a extinção da Renca, em 2017, percebe-se duas constatações que este artigo se propôs a buscar sobre como o agendamento do tema se deu a partir dos seus definidores. O primeiro apontamento é a grande incidência de fontes oficiais. Elas foram identificadas 13 vezes, sendo o senador Randolfe Rodrigues a única em dez oportunidades. Isso demonstra a falta de pluralidade e polifonia de fontes sobre uma temática que exige contextualização multidisciplinar (BUENO, 2007). Além disso, o raro espaço dado aos cidadãos, sejam eles ribeirinhos ou indígenas - principais afetados pela extinção da reserva -, indica a dificuldade dos veículos da própria região em dar voz a esses povos em assuntos de interesse deles. Isso confirma o pressuposto inicial da predominância de fontes de caráter político em detrimento das pessoas de comunidades abrangidas pela Renca.

A identificação dos definidores foi fundamental para verificar outra questão: as síndromes do jornalismo ambiental. As cinco definidas por Bueno (2007) foram identificadas, em especial a do "zoom", que segmenta o debate de assuntos de meio ambiente a um olhar político, econômico, cultural etc., emergindo novamente a inexistência de uma discussão interdisciplinar.

Os resultados da análise da primeira semana do evento apontam que os consumidores das notícias foram agendados sobre a extinção da Renca de forma segmentada, sem pluralidade e polifonia, configurando uma única fonte definidora da notícia - que em sua maioria teve caráter políti- 
co - como atributo salientado (MCCOMBS, 2009). Assim, pode-se inferir um eventual debate na esfera pública pelos cidadãos consumidores das notícias do Diário do Amapá, G1 Amapá e SelesNafes.Com, com nuances semelhantes às encontradas na cobertura, caracterizada pela segmentação e caráter político das fontes oficiais. Essa especificidade, cristalizada pelas síndromes do jornalismo ambiental, sobretudo a do "zoom”, mostra que a cobertura sobre a temática negligencia a investigação profunda dos fatos, fazendo com que os jornalistas não se deem conta de eventuais interesses ocultos aos eventos, menosprezando o confronto de informações que a pluralidade de vozes poderia trazer à tona.

\section{REFERÊNCIAS}

BUENO, Wilson da Costa. Jornalismo Ambiental: explorando além do conceito. Desenvolvimento e Meio Ambiente, v. 15, jun. 2007. Disponível em: <http://revistas. ufpr.br/made/article/view/11897/8391>. Acesso em: 28 nov. 2017.

BUENO, Wilson da Costa. Jornalismo ambiental e transparência corporativa: o marketing verde como estratégia de mistificação. Revista Ação Midiática, v. 1, no 2, dez. 2011. Disponível em: $<$ https://revistas.ufpr.br/acaomidiatica/article/view/26426>. Acesso em 12 mai. 2018

CAVLAK, Iuri. O Golpe Militar no Suriname e a Geopolítica no Platô das Guianas. Revista de Geopolítica, v. 7, n. 1, p. 133-151, 2016. Disponível em: <www. revistageopolitica.com.br/index.php/revistageopolitica/article/view/149>. Acesso em: 26 fev. 2018.

DIÁRIO DO AMAPÁ. Congresso estadual do PSB tem como foco a defesa da Renca, desenvolvimento sustentável e futuro do Amapá. Disponível em $<$ https:// www.diariodoamapa.com.br/cadernos/politica/congresso-estadual-do-psb-temcomo-foco-a-defesa-da-renca-desenvolvimento-sustentavel-e-o-futuro-do-amapa/> . Acesso em 07 jan. 2018.

Randolfe pede apoio do Papa na luta contra a extinção

da Renca. Disponível em < https://www.diariodoamapa.com.br/cadernos/politica/ randolfe-pede-apoio-do-papa-na-luta-contra-extincao-da-renca/>. Acesso em 07 jan. 2018.

MPF-AP complementa ação para atacar novo decreto de

extinção da Renca. Disponível em < https://www.diariodoamapa.com.br/cadernos/ geral/mpfap-complementa-acao-para-atacar-novo-decreto-de-extincao-da-renca/> . Acesso em 07 jan. 2018. 
DORNELLES, Beatriz Correa P.; GRIMBERG, Daniela. Jornalismo Ambiental: análise dos critérios de noticiabilidade na web. Vozes e Diálogo, v. 11, n. 1, 2012. Disponível em <http://meriva.pucrs.br:8080/dspace/bitstream/10923/9728/2/Jornalismo_ Ambiental_analise_dos_criterios_de_noticiabilidade_na_web.pdf $>$. Acesso em: 09 dez. 2017.

G1 AMAPÁ. No AP, aula aberta discute conseqüências da extinção da Renca para a população. Disponível em <https://g1.globo.com/ap/amapa/noticia/no-ap-aulaaberta-discute-consequencias-da-extincao-da-renca-para-a-populacao.ghtml $>$. Acesso em 07 jan. 2018.

. Quatro rios do AP têm peixes com nível elevado de mercúrio, aponta estudo. Disponível em: < https://g1.globo.com/ap/amapa/noticia/quatro-rios-do-aptem-peixes-com-nivel-elevado-de-mercurio-aponta-estudo.ghtml >. Acesso em 7 jan. 2018.

HALL, Stuart; CHRITCHER, Tony et al. A produção social das notícias: O mugging nos media. In TRAQUINA, Nelson (org.). Jornalismo: questões, teorias e “estórias". Insular: Florianópolis, 2016.

HERSCOVITZ, Heloísa. Análise de Conteúdo em Jornalismo. In: Lago C, Benetti M. Metodologia de Pesquisa em Jornalismo. Petrópolis: Vozes; 2007.

LIPPMANN, Walter. Opinião pública. Petrópolis: Vozes, 2010.

MOTTA, Camila Pelegrini. Jornalismo Ambiental em rede e a biodiversidade no foco da mídia. In Anais XXXIII Congresso Brasileiro de Ciências da Comunicação. Caxias do Sul, 2010. Disponível em <http://www.intercom.org.br/papers/nacionais/2010/ resumos/R5-2952-1.pdf>. Acesso em 11 dez. 2017.

MCCOMBS, Maxwell. A Teoria da Agenda: a mídia e a opinião pública. Petrópolis, RJ: Vozes, 2009.

SCHARF, Regina. Economia sustentável é utopia, contradição ou lucro certo? In: BOAS, Sérgio Vilas. Formação \& informação ambiental: jornalismo para iniciados e leigos. São Paulo: Summus, 2004.

SCHMITZ, Aldo. Fontes de notícias: ações e estratégias das fontes no jornalismo. Combook: Florianópolis, 2011.

SELESNAFES.COM. "Absurdo", diz chefe Waiãpi sobre o fim da reserva mineral na Amazônia. Disponível em <https://selesnafes.com/2017/08/absurdo-diz-chefewaiapi-sobre-fim-de-reserva-mineral-na-amazonia/>. Acesso em 07 jan. 2018. 


\section{Exploração mineral na Amazônia: histeria no paraíso.}

Disponível em: <https://selesnafes.com/2017/08/exploracao-mineral-na-amazoniahisteria-no-paraiso/>. Acesso em 07 jan. 2018.

TEIXEIRA, Taís Garcia. Jornalismo ambiental: o desafio da construção da notícia soft news. Vozes e Diálogo, v. 13, n. 02, 2014. Disponível em <http://siaiap32.univali.br/ seer/index.php/vd/article/view/6421>. Acesso em 12 dez. 2017. 